\title{
Visual-Form Learning Analytics: A Tool for Critical Reflection and Feedback
}

\author{
Kelly McKenna \\ Colorado State University, United States \\ ORCID: 0000-0002-6105-389X \\ Beth Pouska \\ Colorado State University, United States \\ ORCID: 0000-0001-6059-7863 \\ Marcia C. Moraes \\ Colorado State University, United States \\ ORCID: 0000-0002-9652-3011 \\ James E. Folkestad \\ Colorado State University, United States \\ ORCID: 0000-0003-0301-8364
}

\begin{abstract}
Accessible learning analytics available from the data within learning management systems, can assist with teaching and learning practices, but often this data is difficult to interpret. Learning analytics, specifically those presented in visual-form, can provide information that supports learners' reflection and guides them to the necessary changes that lead to successful self-regulated learning. This research study utilized photoelicitation methods to prompt learners' reflections of their self-regulated retrieval practice activities, quiz-based learning opportunities, which were qualitatively analyzed. A tool, U-Behavior, was created which was designed to extract students attempt data on the retrieval practice activities which were presented to students as opportunities to study the course content rather than as evaluations of understanding. Upon completion of the retrieval practice activities, learners were presented with their personalized learning analytics in visual-form and prompted to reflect on their learning. Visual-form learning analytics create opportunities for feedback and critical reflection for both instructors and learners and improve student learning. Analysis of the visual-form learning analytics and corresponding reflections highlighted learners' understanding of high-impact learning practices, the realization of intended study behaviors versus engrained behaviors, high score orientation, and a focus on comparisons.
\end{abstract}

Keywords: Learning analytics; Visualizations; Reflection; Spaced retrieval practice

\section{Introduction}

Even the most basic learning analytics (LA) accessible to instructors and administrators through learning management systems (LMS) offer both students and faculty the opportunity to better 
understand student interactions and intentions. Log data can provide information to instructors, institutions, and students, allowing them to make data-driven decisions regarding best practices in course design and improved student success (Dietz-Uhler \& Hurn, 2013). In learning environments that rely on self-regulation, such as online classes or online class activities, "making effective choices and adaptation of learning strategies in response to the emerging needs from the learning environment are critical features of effective self-regulated learning" (Gasevic, Jovanovic, Pardo, \& Dawson, 2017, p. 115). LA, specifically those presented in the visual-form, can provide information that supports learners' reflection and guides them to the necessary changes that lead to successful self-regulated learning.

This study utilized online students LMS learning analytics to create visual representations of the students' behaviors on a self-regulated activity. The visual representations, visual-form LA, were then presented to the students as a tool for reflecting on their learning practices. Visual-form LA consist of the process of representing learner usage data as a visualization. This visualization may take the form of an image, graphic, picture, or any other visual-form.

Visual methodologies were employed and the student reflections and visual-form LA were analyzed by the researchers to identify applications related to the use of visual-form LA in online higher education. The findings from this study ascertained students' application of learning, perfunctory behaviors regarding study habits, assessment emphasis, and affinity for appropriate comparisons.

\section{Literature Review}

\section{High-Impact Learning Practices}

"Learning is an acquired skill, and the most effective strategies are often counter intuitive" (Brown, Roediger, \& McDaniel, 2014, p. 2). One category of effective strategies for learning is high-impact learning practices (HILPs). These practices give students studying and learning strategies varied from most commonly used techniques such as re-reading or route memorization (Brown, Roediger, \& McDaniel, 2014). Some HILPs include reflection, spaced retrieval, interleaving, elaboration, and mental models. The practices help learners identify for themselves what they do not know as compared to what they do know in memorization of what is provided.

Each HILP is unique but the intention of each is to improve learning. According to Brown et al. (2014), "reflection can involve several cognitive activities that lead to stronger learning" (p. 27). One of those activities is retrieving new knowledge or skill from memory. The retrieval must be repeated several times, in spaced out sessions, for the recall to require cognitive effort and produce knowledge that can be retrieved more readily and applied in a variety of scenarios. This process is known as spaced retrieval practice (SRP). SRP is a HILP that consists of retrieving new knowledge or skill from memory several times in spaced out sessions (Brown et al., 2014). Another HILP is interleaved practice. Interleaved practice consists of alternating between subjects or content rather than blocked practice (studying the same content repeatedly). Interleaving the practice of two or more contents or skills have been shown to increase mastery and long-term retention as well as to help discriminate between problems and to select and apply the correct solutions from a range of possibilities (Brown et al., 2014). 


\section{Use of Quizzes as HILP}

One classroom example is the use of low-stakes quizzes to get students to retrieve and practice over time (Roediger, Agarwal, McDaniel, \& McDermott, 2011). In this strategy, the quizzes are used as a learning tool rather than simply as a summative assessment. Testing enhances learning and retention of the material, as well as the metacognitive use of tests, which informs learners regarding what they do and do not know, allowing them to concentrate study efforts on topics they do not know.

Several studies have argued that effective online quizzes can enhance learner engagement and have a positive impact in student's learning outcomes (Balter, Enstrom, \& Klingenberg, 2013; Berrais, 2015; Cohen \& Sasson, 2016; Gikandi, Morrow, \& Davis, 2011; McDaniel, Wildman, \& Anderson, 2012; O'Dowd, 2017). Online quizzes provide opportunities for documenting and monitoring evidence of learning for both learners and teachers, while giving learners multiple opportunities to demonstrate their learning and insight about their understanding (Gikandi et al., 2011; O'Dowd, 2017). McDaniel et al. (2012) found evidence that quizzing along with feedback can be an effective technique to assist mastery and retention of content and that retrieval practice facilitates fluent recall of facts. Balter et al. (2013) observed that almost all learners appreciated having short online quizzes just after learning some new content and some of them changed their view on how much they knew of the material covered in the course and altered their study habits, studying harder or earlier. Cohen and Sasson (2016) found that randomization and multiple attempts in quizzes empowers students regarding their learning and contributed to student's personal self-reflection.

\section{Learning Analytics as a Formative Tool}

Learning analytics (LA) is the measurement, collection, analysis and reporting of data about learners and their contexts, for purposes of understanding and optimizing learning and the environments in which it occurs (SoLAR, 2011). In technology-aided classrooms, data about student's usage of electronic tools is extensive (Gasevic, Jovanovic, Pardo, \& Dawson, 2017). Utilizing this data for student and instructor knowledge transforms the data into LA with specific goals aiding students and faculty. There are two primary principles regarding the use of LA: "to understand and to optimize learning and learning environments in which learning occurs" (Gasevic, Jovanovic, Pardo, \& Dawson, 2017, p. 113). Some insights can be directed to class-level where learners immediately benefit and others to course-level where learners benefit more in the future planning. 


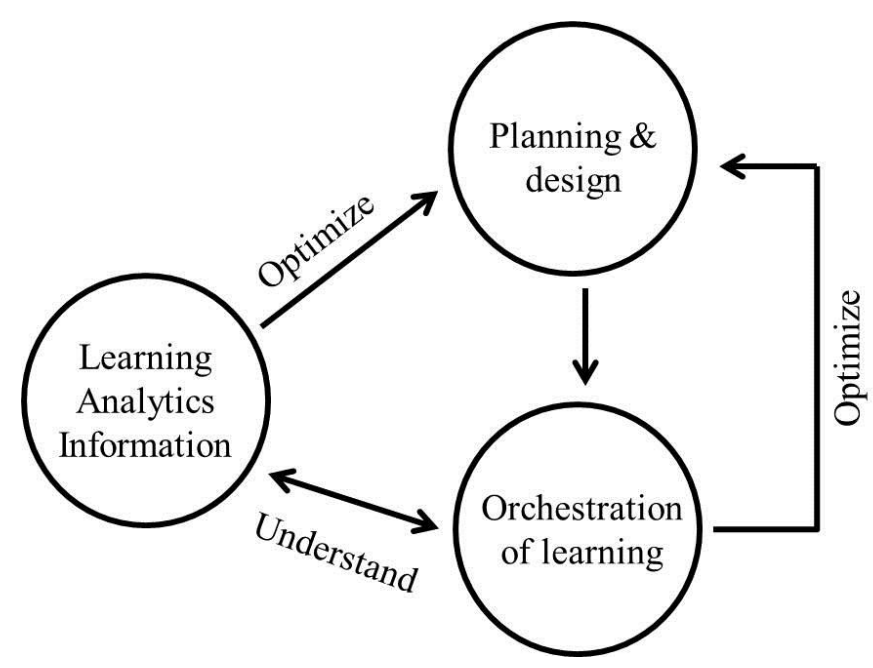

Figure 1. Data from Student Work at the Class Level Creates LA that Help in Understanding Class Information That Then Feeds into Optimizing Course Planning and Design

At the course-level, LA are often used as a needs analysis for the learners in the context of the course and its topics. This information, in part, contributes to the course design including development of curriculum goals and objectives based on actual data of student progress and behavior. LA presents faculty and administrators the opportunity to make overall assessments of learning and effectiveness of learning behaviors in the course as a whole. Dietz-Uhler and Hurn (2013) explain the benefits of LA for faculty and course planners to bridge the gaps in student understanding and behaviors with the goals and outcomes desired of the course.

At the class level, "instructors could derive specific recommendations for their students with respect to the strategies they need to follow and corrective measure they can take to optimize their students' approaches to learning" (Gasevic et al., 2017, p. 123). In making these recommendations, the instructor must be cognoscente of the learning behaviors students have intentions to use and what is actually being implemented so as to build on, rather than divert from, student's own self-directed practices. LA provide instructors with the data that is helpful for making recommendations for individual student improvement.

While learning analytics are often technology driven in their initial data mining and manipulation, it is ultimately "...a soft technology in that it involves the orchestration of human processes" (Wise, 2014, p. 203). This orchestration requires a common method or language, and images have been used to help with this type of communication. Visualizations of user actions can be used in technology enhanced learning to support the learning process, increase awareness for learners and teachers, and to support self-reflection (Beheshitha, Hatala, Gašević, \& Joksimović, 2016; Govaerts, Verbert, Duval, \& Pardo, 2012; Kruse \& Pongsajapan, 2012). Information portrayed in images can create a deeper understanding of the material or processes (Harper, 2002).

Furthermore, Images are "unique sources of evidence" that create opportunities for dialogue (Rose, 2007, p. 238) and making meaning from the data can come from the creation of a visualization based on the data. Materials such as photographs, videos, drawings, collages, maps, graphs, and diagrams are just some forms of potential visualizations (Harper, 2002; 
Wagner, 2006). Some examples of visual learning analytics tools are: eLAT (Dyckhoff, Zielke, Chatti, \& Schroeder, 2011) which was designed to be used by teachers to monitor and to analyze their teaching; Snapp (Bakharia, \& Dawson, 2011) that enables instructors to visualize the evolution of participant relationship within a forum; and ViMoodle (Aguilar, Therón, \& Peñalvo, 2008 ) that provides three kinds of visualizations (a word cloud of some tools, a snail graph map of the frequency of actions in the LMS, and a social network graph map of relationship and frequency of students and teachers activities). Given that LA are intended to effect human learning, a growing amount of focus is being placed on the visualization of information in an effort to inform student behaviors that support long-term learning and retention (Alhadad, 2018).

Based on the background and the problem described above, the leading research question for the current study was the following: How does the integration of visual-form LA contribute to teaching and learning practices?

\section{Methods}

Throughout the course students were assigned self-regulated retrieval practice activities (RPAs), class content quiz-based learning opportunities, in which students were instructed to implement the HILPs discussed throughout the course. Following the final RPA, learners were presented with a visual representation of their personalized RPA log data in the form of visual-form LA. The visual-form LA were then utilized as a reference tool for prompted reflection questions designed to create an opportunity for students to reflect on their semester-long self-regulated RPA learning behaviors.

\section{Settings and Participants}

This project was initialized in an online class for organizational leaders as part of a Masters of Education program at a Research 1, land-grant university, in the Fall 2017 semester. A convenience sample of twenty-four working, adult learners were registered for the course with 19 consenting to be included in the research. The course focuses on the science of learning and includes an objective of developing connections between supportive learning theories and applying these to course assignments.

\section{Data Collection}

There were two phases of data collection in this study. In the first phase, usage data was collected (see description below) and transformed into visual-form LAs. In phase two, the visualform LA were utilized to support student reflections. The photo-elicitation method was used as a process of gathering written accounts and interpreting meanings of the visuals. 


\section{Phase I}

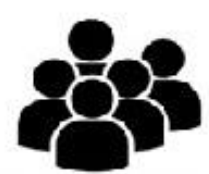

Students Complete RPAs

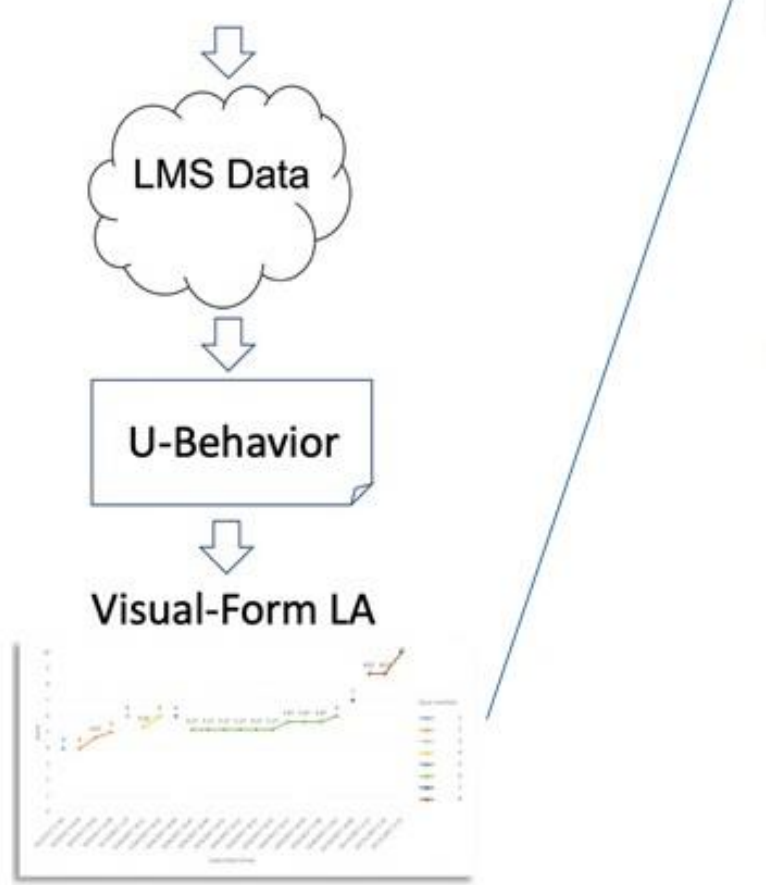

Phase II

Visual-Form LA

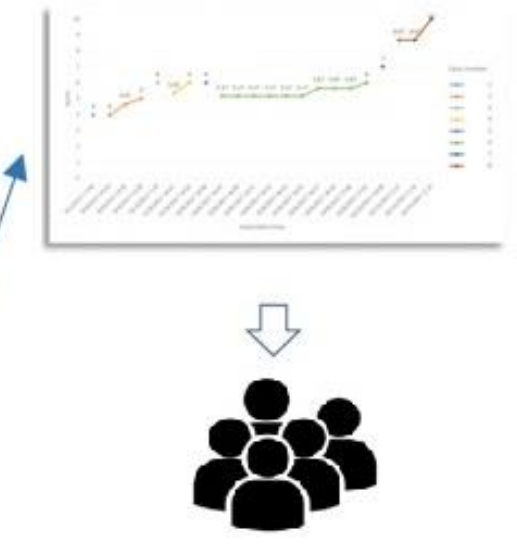

Students Complete Reflections

Figure 2. Two Phase Process. RPA Data Collection/Visual-Form LA Creation, and Student Reflection

\section{Phase 1: LMS Data Extraction and Creation of Visual-form LA}

In order to build the visual-form of learners' RPA attempt behavior, we extracted quiz-logfile data from the LMS. A Python-based application (U-Behavior) was developed by the researchers to extract data from quiz submission attempts and use those to generate the visual-form LA in the format of a graphical representation of the learners' RPA attempt behavior. We used Spyder development environment, running Python 3.7 version, to build and run the U-Behavior application. Figure 3 provides an example of one student's visual-form LA.

The X-axis reflects the RPA submission times composed of date and time of each attempt and the $\mathrm{Y}$-axis represents the score obtained in each attempt. A colored node represents each attempt and each color signifies one of the RPAs offered during the class. The RPAs taken in chronological succession were connected by trend lines. A node that is isolated (see the point labeled " 7 " in figure 3) can indicate that the student completed the RPA once or it may indicated that the student was interleaving their practice if they choose to test their knowledge by intermixing the RPAs across time (see figure 5). 


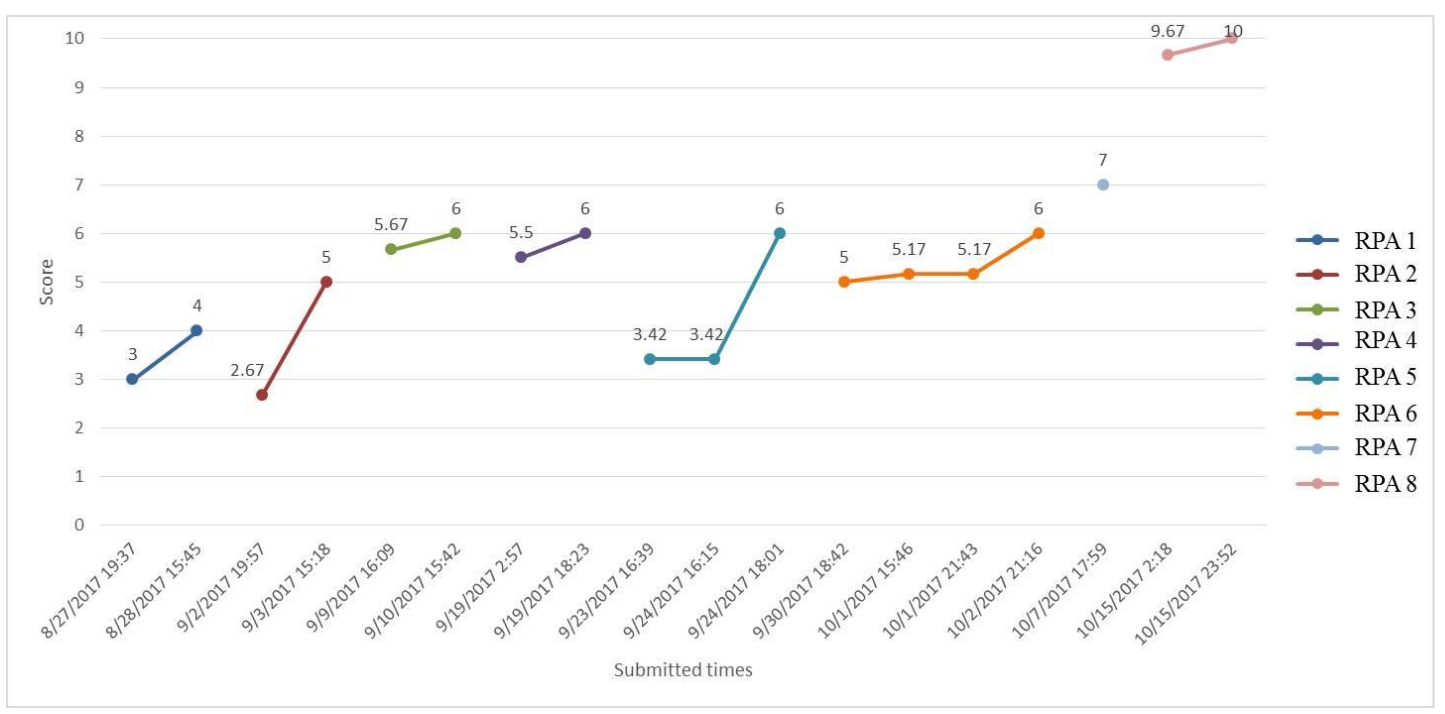

Figure 3. Example of a Student's Visual-Form LA

\section{Phase 2: Photo-elicitation}

Photo-elicitation is a visual research method that entails image creation, analysis, and reflecting on visual images (Harper, 2002; Rose, 2007). Collaborative visual creation, the integration of visuals in research where there is a connection between the visual and the participant, is one visual methodological technique common in photo-elicitation research (Banks, 2007). The second form of data collected was in the form of student reflections which were in response to the visual-form LA created in phase one. Following creation of the visual-form LA, students were prompted with a series of reflective questions and asked to reflect on the visual representation (visual-form LA) of their learning behaviors. These reflection prompts incorporated questions from two perspectives: personal reflection of the RPAs as the student and from the perspective of an instructor reviewing the RPA data.

Personal reflection questions included:

- did the course content, learning about the science of learning and HILPs, affect your RPA behavior;

- which learning practices are reflected in your visual-form LA;

- is a visual representation beneficial to your learning;

Instructor perspective questions included:

- what does the visual-form LA tell you, the instructor, about the student;

- As the instructor, what course changes would you make based on the extracted LA.

\section{Data Analysis}

Students' visual-form learning analytics and photo-elicitation responses were analyzed and coded for the emergence of visual and written themes. We defined a coding protocol in the initial stages of reviewing the reflective responses and visuals to confirm the same coding process was adhered to by all researchers and to ensure inter-rater reliability. The rudimentary analysis included the initial emergence of codes from the student reflections about their visual- 
form LA. On subsequent independent reviews of the data (reflections, and visual-form LA) each researcher highlighted several initial codes. Each researcher then presented and briefly explained their codes to the team, which allowed the group to combine similar codes and collectively define four themes. The reflections were then analyzed based on the four identified themes and support for each of the themes was extracted. The visual-form LA were then analyzed and the representation of any identified theme was tabulated (high score-oriented, HILPs). In this study, 19 learners completed 124 RPAs with 284 total attempts. Discussions among the researchers continued throughout the data review, analysis, and reporting of the combined themes, particularly regarding candid ideas from the students versus prompted themes based on the reflection prompts.

\section{Findings and Discussion}

Four themes emerged from analysis of the visual-form LA and reflection activity. The four themes were: HILPs understanding, individual study behaviors-intent vs. engrained practices, high score-orientation, and the use of comparisons to evaluate work and efforts based on the visual-form LA.

\section{High Impact Learning Practice Understanding}

In the reflections, learners described HILPs such as interleaving, elaboration, summarization, reflection, content retrieval, repeated elaboration, and spaced retrieval. The integration of HILPs and lack of utilization were both included in the reflective responses, as were illustrations of lack of understanding regarding the various HILPs.

Students completed all RPAs before seeing their data visualized as visual-form LA, but learners remarked that the visualizations of their scores offered additional learning practices: "If reflection is truly an effective form of learning, this tool really supports that action and personal growth" (Student O). One student specifically identified the reflection opportunity after all activities were completed: "It's nice to see it in retrospect, I think. These reflection questions were also helpful to try to think back on learning and apply the analysis to our learning" (Student M).

The visual-form LA showed learners their efforts throughout the semester in one combined image:

I can see the correlation between spacing retrieval and struggling a bit to retrieve information from long term memory, and the depth of learning that happens with that information, the connections with previous knowledge and the contextual developments that occur in learning. (Student $\mathrm{L}$ )

In student G's visual-form LA, we see the practice of spaced retrieval in the first four activities. While three of the four activities ended with a perfect score, the date and time between attempts supports their reflection of practicing spacing as their HILP (see Figure 4). 


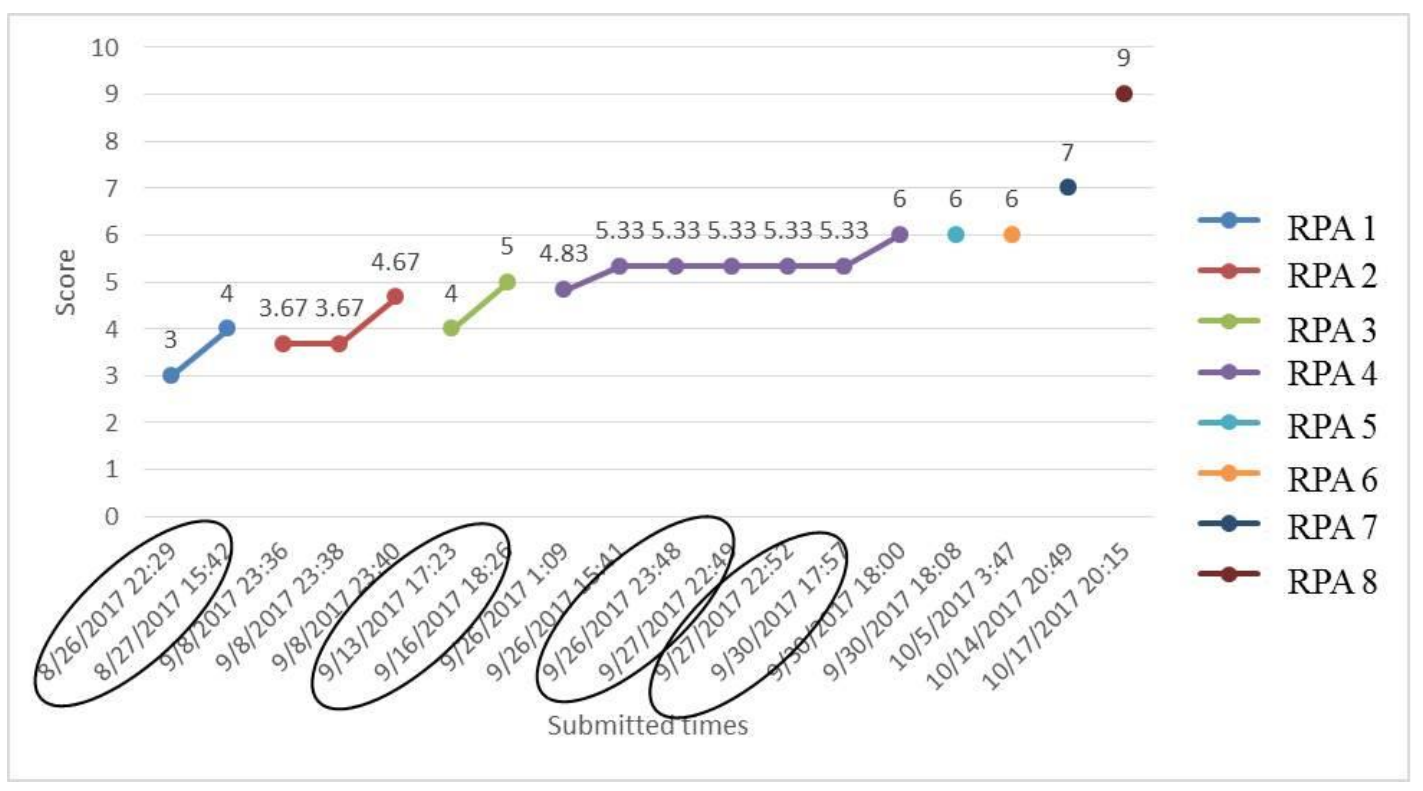

Figure 4. Student G's Visual-Form LA: Example of Spaced Retrieval Practice

In comparing the student's reflective responses to the visualizations each student received, one student appeared to have a misperception of the HILPs. The student's visual-form LA did not show attempt data that would indicate the use of particular HILPs, but their written reflections stated they used specific techniques. This disconnect between the meaning of the practice as presented in the class and the student's explanation of a practice not represented in the visualform LA could be an indication of misunderstanding of the content. This realization of potential lack of understanding is very beneficial to an instructor and might not have been identified without the combination of the visualization and reflective response. Very few of the students' visualizations clearly showed a specific HILP in use in all of the RPAs they completed, but they depicted varied strategies or behaviors throughout the attempts/semester, especially in failing to consistently practice interleaving. Since multiple HILPs were presented in the course, learners may have approached each RPA with different strategies/methods. For example, Student M provided this reflection as depicted in their visual-form LA for RPAs two and three, but not the other four in the course:

With each RPA having a time stamp, it [the visual-form LA] also showed I didn't re-take any of them [the RPAs] immediately after the first attempt. I took the suggested recommendation and studied a little more, then took it a day or two later-showing interleaving and some desirable difficulty. (Student M) 


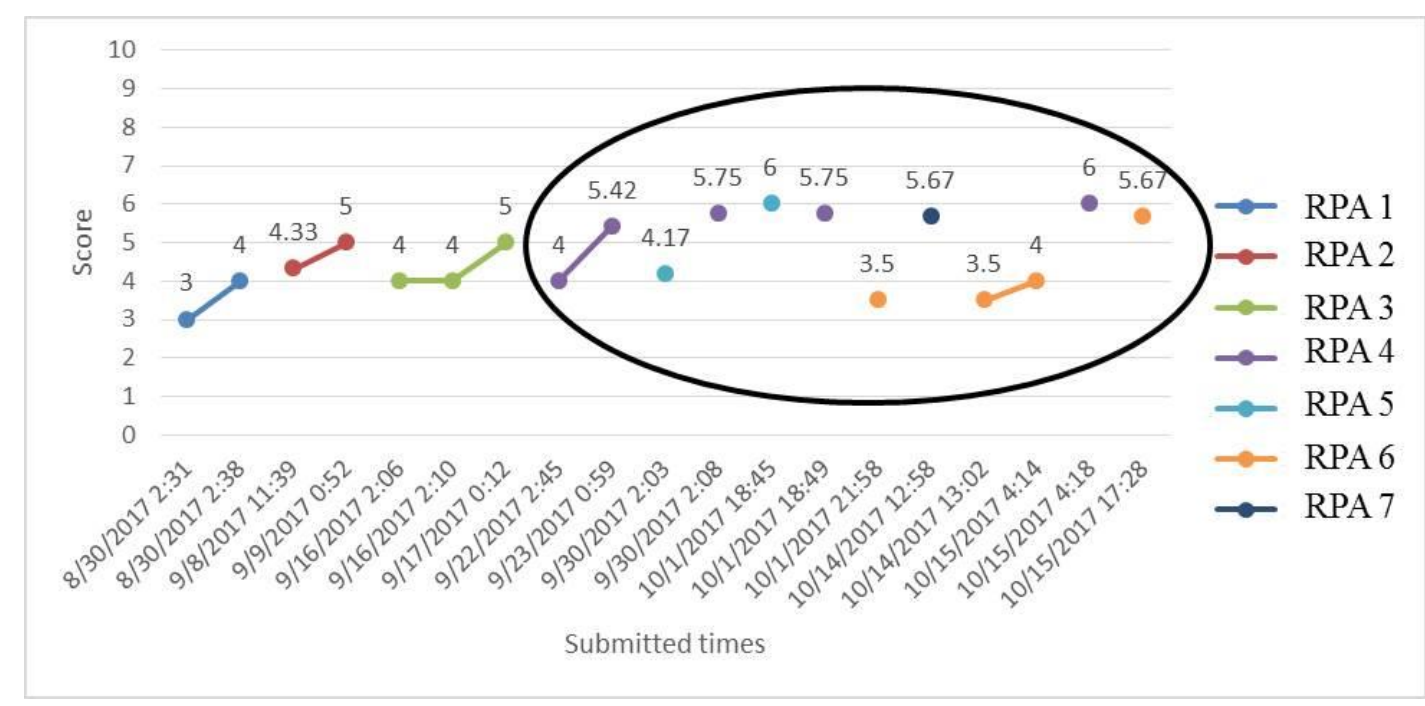

Figure 5. Student M's Visual-Form LA: Example of Interleaving

\section{Individual Study Behaviors-Intention vs. Engrained Practices}

Within the reflections, several students commented on their intention to utilize HILPs in their RPA attempts, but found themselves returning to routine or habitual learning practices. "I fell back into old habits, even though I knew spaced practice would be better. I often took the tests really quickly to try and 'check it off the list'" (Student O). However, the battle between a student's intention and their engrained practices offered an opportunity regarding their learning strategies: "As the course progressed I found myself taking a quiz not to demonstrate performance but as a review of what I had learned" (Student $H$ ). Many of the learners recognized the opportunity to complete the RPAs employing HILPs, but found it challenging to connect the strategies to their study practices.

What is unfortunate is that everything I have learned I find so much value in, but it seems as though shifting that mindset is harder than I anticipated. I did take the quizzes at least a day later, which was new for me, but I found myself having a harder time going back when I did do well on the quizzes. (Student E)

Looking at the visual-form LA showed some attempts of learners following various HILPs in some of the RPAs, but few (if any) completed every RPA multiple times, which was one indication of learning practices being used. Of all the RPAs completed, 146 (59\%) had multiple attempts. The overall learner attempts mean was 2.3 , but the mean attempt for learners completing the RPA multiple times was 3.3. In review of the visual-form LA for each individual, we determined that a total of 10 learners attempted spacing, two attempted interleaving and 18 practiced retaking. Learners' responses confirmed the division between their intentions of completing the RPAs with various learning strategies and the actual application. "The learning objectives of the purpose of a retrieval practice activity were not actually practiced via the quizzes, but they were acknowledged" (Student C). However, some have changed their behavior based on what they learned in class, Student $R$ stated, "From this course, I have learned the importance of interleaved practice and trying again later. After each quiz, I would review the material that I missed and reflected on why I chose that answer, and why it was incorrect." This statement indicates the learner is practicing both interleaving and reflection, two HILPs discussed in the class. 


\section{High Score Orientation}

While not specifically asked in the survey about their motivations, many of the students gave solid indication of their intentions and motivations explaining how and why they participated in the RPAs as the visual-form LA depicted. In reviewing the visual-form LA, 14 of the 19 students appeared to have been seeking the high score in the majority of the RPAs they attempted as indicated by attaining the high score and then ceasing their attempts; no students re-attempted an RPA after the high score was realized. Only four learners achieved perfect scores on all RPAs they attempted and $67 \%$ of all RPAs attempted reached the high score. Considering the reflective responses, only seven students indicated their high score orientation. For example, "The graph depicts my eagerness to complete the quiz in hopes of receiving a high score. It was my goal to achieve full marks while not exhausting my remaining takes." (Student A). Another student (C) explained their high score orientation: "The pursuit of 'maximum point value' served as the conditioned objective and since the grading rubric for the class incorporated only the highest score, once I achieved that score, I checked it off the mental 'to-dos.' I know this is completely counter [to] the assignments' purpose in this class." The RPAs had a very low point value in the overall grade of the class, and the intention of the activity was presented as a cognitive tool to study and practice the methods of the course, not a high-stakes evaluation of their understanding.

Figure 6 was created to spotlight the high score orientation. The two different students retook the RPA when they did not earn full points on the first attempt and continued retaking them only until they earned full points. This practice of not continuing after a high score is earned defeated the intent of the activity as an opportunity to implement the HILPs being discussed. (Note: Student P did not attempt quiz 8 during the timeframe of the study.)

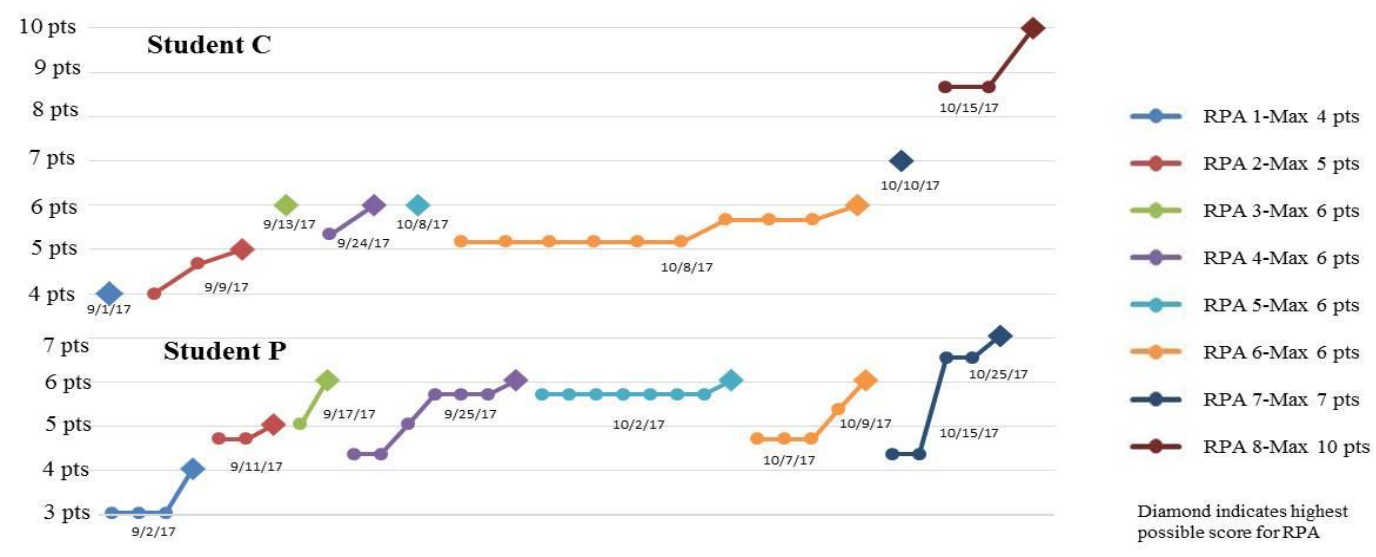

Figure 6. Examples of High-score Orientation

Learners' final grade alone on each RPA would not represent the high score-oriented strategy due the option for multiple attempts and the opportunity to receive the highest score realized, however the visual-form LA clearly presents high score orientation. These visualizations of 
students' activity provided both the students and researchers the insight in differences between understanding the topics of the course and applying them to their own studies.

Although the practice of high score orientation, as seen above, was contrary to the course objectives, most learners indicated in the reflective responses that they were aware of not practicing HILPs, as intended. The visual-form LA reminded learners about their focus and potential mis-alignment with the objective of the RPAs. Student $C$, a high score-oriented student, reflected that:

The graph is useful for my learning, because it indicates that I didn't actually practice retrieving information. I didn't use that tool in a way that enhanced my true learning from the course. And honestly, it sort of bums me out because I missed an opportunity.

This learner's statement regarding the visual-form LA offers an honest reflection that they missed the opportunity for learning presented and instead sought a high score. In pursuit of the high score, Student $C$ had the highest number of attempts on a single RPA, 10, which was the maximum number of attempts allowed on the RPAs. Of these, the first five attempts had the same score and all ten attempts were completed in quick succession over a period of 14 minutes, which provides basis for the assumption that no HILP was used.

One learner's reflection showed a change in their intention and shift from the initial motivation of the high-score after experiencing the learning activity:

I didn't like it at first, because I want to score a perfect $100 \%$. I was frustrated after only getting two questions right on my first RPA. After getting used to taking these, I began to feel more at ease, which I believe also helped improve my performance. I wasn't stressing on getting the correct answer. Instead I was thinking smarter about which answers were most correct from what I remembered. I found this exercise to be very helpful and it has really improved my retention of the materials. (Student I)

Student I retook $100 \%$ of the RPAs and achieved a high score on $75 \%$ of the activities they completed. The visual-form LA show progressive scores throughout the attempts and paring the visual depictions with the learners' reflections gave us insights into the learners' desires to frequently reach the highest score.

\section{Use of Comparisons}

Learners frequently expressed their thought processes using comparisons. This included comparisons of their own visual-form LA and interest in comparing to others. Some compared their own attempts on a single RPA as the grade-driven outcome of the learning objective. "The one overarching thing I could conclude was that between attempts, some studying and learning was being done because the trend is all upward/positive. There were no lower scores than a previous attempt." (Student M)

Learners also compared their attempts on different RPAs, "the graph was useful in that it showed me my performance throughout the semester. I forgot my performance in the beginning of the semester to be reminded was helpful. It also brings light to the areas you need to improve." (Student E)

Additionally, while learners were not given the data of other students, several commented on the interest in seeing how and what others were doing when completing the RPAs. 
It might be helpful to show a composite result (of a previous class, perhaps) to the current class about mid-way in a course. If this information could compare and contrast grade improvements that were spaced out as opposed to taken in quick succession. This could reinforce the point that spaced learning is effective. (Student $O$ )

The idea of comparing one's score to an average or mean showed the learner's desire to reach a standard as compared to accomplishing their own learning potential. Even in a personal reflection activity, which should be focused on self, the desire to compare to others and their motivation/approach for the activities was present.

\section{Implications}

The integration of visual-form LA into the design of a course contributes to teaching and learning by creating opportunities for both instructors and students. In this study we found evidence that visual-form LA can be used by instructors as a tool for feedback, and when provided to the learners a powerful tool for critical reflection.

Visual-form LA can be provided directly to students as feedback or as a tool for instructors to gather information for feedback. Instructors can use visual-form LA to better understand students' learning behavior, identifying their strengths and areas that need to be improved. Visual-form LA allow instructors to analyze students' learning and based on the data they can provide personalized feedback to the learner. Visual-form LA containing learners' individual participation data can also be provided directly to students as a form of feedback. It can provide students with "big picture" feedback related to their learning behavior in the course allowing instructors to then guide overall learning in the context of the course. Facilitating students' learning should be the ultimate goal of instructor feedback.

The use of visual-form LA can also contribute to improved learning strategies as it presents information that is useful for both instructors and students to reflect on. Creating visual-form LA from various activities will look different based on the raw data available and the desired behavior, but helping students to better understand how they behave, and how that behavior is related to learning may lead to improved learning strategies. Presenting learners with visualform LA creates opportunities for them to reflect on and understand their practices, changing and improving their learning strategies when they think it could be beneficial for them.

\section{Limitations and Future Research}

Future research will work on pedagogical modifications focused on determining ways to encourage additional reflection and to modify learning behaviors. This may include exposing students to the visual-form LA earlier in the semester or more often throughout the semester as this project did not present students with the visual representation for reflection until all of the RPAs were completed. This eliminated the opportunity for students to have personal data to support modifying their self-regulated learning behaviors. We would like to understand if additional exposure has an impact on RPA attempt behavior. Additionally, students were only presented with their own learning analytics. In future research we plan to examine how performance is impacted by providing learners with generic visual-form LA (spaced retrieval, interleaving etc.) from previous students. 


\section{Conclusion}

The visual-form LA utilized in this research were created by the researchers and instructor from raw LMS data of student activity on quiz-like RPAs. The question of understanding the contributions of these visualizations for both learners and instructors were satisfied through analysis of the visual-form LA and the corresponding student reflections. Four primary findings emerged including learners': deeper understanding of the HILPs, returning to engrained learning habits vs. initial intentions, orientation towards earning the highest score possible, and employing comparisons to understand their visualizations. Faculty have the opportunity to use visual-form LA as a form of feedback to deepen learners' understanding and to improve student learning strategies through critical reflection.

\section{References}

Aguilar, D. A. G., Therón, R., \& Peñalvo, F. G. (2008). Understanding Educational Relationships in Moodle with ViMoodle. 2008 Eighth IEEE International Conference on Advanced Learning Technologies, 954-956. Santander, Cantabria.

Alhadad, S. S. (2018). Visualizing data to support judgement, inference, and decision making in learning analytics: Insights from cognitive psychology and visualization science. Journal of Learning Analytics, 5(2), 60-85.

Bakharia A. \& Dawson S. (2011). SNAPP: a bird's-eye view of temporal participant interaction. 1st International Conference on Learning Analytics and Knowledge, 168-173. Vancouver, British Columbia, Canada.

Balter, O., Enstrom, E., \& Klingenberg, B. (2013). The effect of short formative diagnostic web quizzes with minimal feedback. Computers \& Education, 60(1), 234-242.

Banks, M. (2007). Using visual data in qualitative research. Los Angeles: Sage.

Beheshitha, S. S., Hatala, M., Gašević, D., Joksimović, S. (2016). The role of achievement goal orientations when studying effect of learning analytics visualizations. LAK'16 Proceedings of the Sixth International Conference on Learning Analytics \& Knowledge, 54-63. Edinburgh, UK.

Berrais, A. (2015). Using online Moodle quizzes to support the teaching of mathematics to foundation engineering students. QScience Proceedings: Engineering Leaders Conference 2014, 8.

Brown, P. C., Roediger, H. L., \& McDaniel. M. A. (2014). Make it stick: The science of successful learning. Cambridge, MA: Harvard University Press.

Cohen, D. \& Sasson, I. (2016). Online quizzes in a virtual learning environment as a tool for formative assessment. Journal of Technology and Science Education, 6(3), 188-208.

Dietz-Uhler, B \& Hurn, J.E. (2013). Using learning analytics to predict (and improve) student success: A faculty perspective. Journal of Interactive Online Learning, 12(1), 17-26.

Dyckhoff, A.L., Zielke, D., Chatti, M.A., \& Schroeder, U. (2011, July). eLAT: An exploratory learning analytics tool for reflection and iterative improvement of technology enhanced learning. Paper presented at the 4th International Conference on Educational Data Mining. Eindhoven, The Netherlands. 
Gasevic, D., Jovanovic, J., Pardo, A., \& Dawson, S. (2017). Detecting learning strategies with analytics: Links with self-reported measures and academic performance. Journal of Learning Analytics, 4(2), 113-128.

Gikandi, J. W., Morrow, D., \& Davis, N. E. (2011). Online formative assessment in higher education: A review of the literature. Computers \& Education, 57(4), 2333-2351.

Govaerts, S., Verbert, K., Duval, E. \& Pardo, A. (2012). The student activity meter for awareness and self-reflection. CHI'12 Extended Abstracts on Human Factors in Computing Systems, 869-884.

Harper, D. (2002). Talking about pictures: A case for photo elicitation. Visual Studies, 17(1), 1326.

Kruse, A. \& Pongsajapan, R. (2012). Student-centered learning analytics. CNDLS Thought Papers, 1-9.

McDaniel, M. A., Wildman, K. M., \& Anderson, J. L. (2012). Using quizzes to enhance summative-assessment performance in a web-based class: An experimental study. Journal of Applied Research in Memory and Cognition, 1, 18-26.

O'Dowd, I. (2018). Using learning analytics to improve online formative quiz engagement. Irish Journal of Technology Enhanced Learning 3(1). Retrieved on 11 November 2018 from https://doi.org/10.22554/ijtel.v3i1.25

Roediger, H. I., Agarwal, P. K., McDaniel, M. A., \& McDermott, K. B. (2011). Test-enhanced learning in the classroom: Long-term improvements from quizzing. Journal of Experimental Psychology: Applied, 17(4), 382-395. doi: 10.1037/a0026252

Rose, G. (2007). Making photographs as part of a research project: Photo-elicitation, photodocumentation and other uses of photos. In G. Rose (Ed.), Visual methodologies: An introduction to the interpretation of visual materials ( $2^{\text {nd }}$ ed.) (pp. 237-256). Thousand Oaks, CA: Sage.

Society for Learning Analytics Research. (2011). Open learning analytics: An integrated \& modularized platform [Concept paper]. Retrieved on 11 November 2018 from http:/solaresearch.org/OpenLearningAnalytics.pdf.

Wagner, J. (2006). Visible materials, visualized theory, and images of social research. Visual Studies, 21(1), 55-69.

Weinstein, C. E., Husman, J., \& Dierking, D. R. (2000). Self-regulation interventions with a focus on learning strategies. In P. R. Pintrich \& M. Boekaerts (Eds.), Handbook on selfregulation (pp. 727-747). New York: Academic Press.

Wise, A.F. (2014). Designing pedagogical interventions to support student use of learning analytics. LAK'14 Proceedings of the fourth International Conference on Learning Analytics \& Knowledge. Indianapolis, IN. http://dx.doi.org/10.1145.2567574.2567588

Correspondence: Kelly McKenna, Assistant Professor, Adult Education and Training, School of Education, Colorado State University, Fort Collins, Colorado, United States 